\title{
Profil Penggunaan Obat pada pasien Hipertensi di Puskesmas Marawola Periode Januari - Maret 2017
}

Syafika Alaydrus

Akademi Farmasi Medika Nusantara Palu

\begin{abstract}
ABSTRAK
Kesehatan adalah hak asasi yang patut didapatkan oleh semua warga Negara Indonesia. Hal ini tentunya sangat berhubungan erat dengan sistem pelayanan kesehatan khususnya dibidang farmasi. Tujuan penelitian ini adalah untuk mengetahui seberapa besar pola peenggunaan obat pada penyakit hipertensi di puskesmas Marawola. Penelitian ini menggunakan desain penelitian deskriptif yaitu penelitian yang dimaksudkan untuk mengangkat fakta, keadaan dan variabel yang terjadi selama penelitian berlangsung dan menyajikan apa adanya. Hasil peneitian ini menunjukan bahwa penderita penyakit Hipertensi berdasarkan jenis kelamin Laki - laki (45,74\%) dan perempuan $(54,26 \%)$. Berdasarkan usia $<40$ tahun $7,45 \%$, usia $40-49$ tahun $25,53 \%$, usia $50-59$ tahun $30,85 \%$, usia $60-69$ tahun $19,15 \%$, usia $70-$ 79 tahun $13,83 \%$ dan usia $>80$ tahun 3,19\%. Berdasarkan penggunaan obat Paracetamol 13,32\%,
\end{abstract}

\section{PENDAHULUAN}

Kesehatan adalah hak asasi yang patut didapatkan oleh semua warga Negara Indonesia. Hal ini tentunya berhubungan erat dengan sistem pelayanan kesehatan khususnya dibidang farmasi. Sistem pelayanan kesehatan diselenggarakan dengan upaya Promotif, Preventif, Kuratif dan Rehabilitatif. Pembangunan kesehatan dilakukan untuk
Asam mefinamat 2,35\%, Ibuprofen 0,26\%, Isosorbid dinitrat 17,23\%, Nifedipin 1,83\%, Dopamin 0,26\%, Diltiazen 0,52\%, Captopril 19,06\%, Propanolol 18,54\%, Bisoprolol 1,57\%, Amlodipine 13,84\%, Nimodipine 5,48\%, Amdixal 0,26\%, Ceremax 0,26\%, HCT 1,05\%, Bunazosin 0,26\%, Dobutamine $0,78 \%$, Digoksin 2,87\%, Pentoksifilin 0,26\%. Berdasarkan tepat dan ketidak tepatan penggunaan obat diperoleh tepat $100 \%$ tidak tepat $0 \%$. Standar yang digunakan yaitu Depkes RI. Direktorat Jendral Bina Kefarmasian dan Alat Kesehatan dan Direktorat Bina Farmasi dan Klinik, pharmaceutical care untuk penyakit hipertensi.2005.

Kata kunci : $\quad$ Obat, Hipertensi, Resep

Penulis korespondensi :

Syafika Alaydrus

Akademi Farmasi Medika Nusantara Palu

Syafikaalaydrus39@gmail.com

meningkatkan derajat kesehatan

masyarakat dalam upaya peningkatan kualitas hidup kesejatraan masyarakat. Upaya yang dapat mendukung keberhasilan pembangunan kehehatan tersebut adalah tersedianya obat - obatan dan alat kesehatan yang memadai, berkualitas dan terdistribusi secara merata sehingga manfaatnya dapat dirasakan oleh 
seluruh kalangan masyarakat (Tan Hoan Tjay,2008).

Obat merupakan semua zat baik kimiawi, hewani, maupun nabati yang dalam dosis layak dapat menyembuhkan, meringankan atau mencegah penyakit berikut gejalanya (Sutrisni,dkk,2006). Obat adalah semacam zat baik kimiawi maupun tumbuhan yang dalam dosis layak maupun mempengaruhi organorgan tubuh agar berfungsi secara normal. Pengertian lain menyebutkan bahwa obat adalah suatu zat yang digunakan untuk diagnosis pengobatan, menyembuhkan atau mencegah penyakit pada manusia atau hewan (Saraswati, S.2009). Hipertensi atau tekan darah tinggi adalah kondisi kronis dimana tekanan darah pada dinding arteri ( pembuluh darah bersih ) meningkat. Kondisi ini dikenal sebagai pembunuh diam - diam karena jarang memiliki gejala yang jelas. Satu - satunya cara untuk mengetahui apakah seseorang mengidap penyakit hipertensi adalah dengan mengukur tekanan darah orang tersebut. Penyebab penyakit hipertensi ini belum bisa dipastikan lebih dari 90 persen kasus, namun seiring bertambahnya usia kemungkinan seseorang untuk menderita penyakit ini juga meningkat.
Hipertensi atau tekanan darah tinggi adalah suatu gangguan pembuluh darah yang mengakibatkan suplai oksigen dan nutrisi dibawah oleh darah, terhambat sampai ke jaringan tubuh yang membutuhkannya. Hipertensi adalah suatu keadaan yang dimana seseorang mengalami peningkatan tekanan darah diatas normal yang mengakibatkan tingginya angka kesakitan dan angka kematian. Hipertensi atau tekanan darah tinggi adalah penyakit kelainan jantung dan pembuluh darah yang ditandai dengan peningkatan tekanan darah. Menurut WHO seseorang didiagnosa menderita hipertensi apabila tekanan sistolik pada saat istrahat melebihi 160 $\mathrm{mmHg}$ atau dimana tekanan diastolic melebihi $95 \mathrm{mmHg}$. Sementara menurut American Heart Association seseorang didiagnosa menderita hipertensi apabila tekanan sistolik melebihi $140 \mathrm{mmHg}$ dan diastolic melebihi $90 \mathrm{mmHg}$. Riset kesehatan dasar pada tahun 2013 menunjukan bahwa penderita hipertensi yang berusia 18 tahun mencapai 28,8 persen dari jumlah keseluruhan penduduk Indonesia. Dari jumlah keseluruhan angkat tersebut mengatakan bahwa perempuan lebih banyak 6 persen 
disbanding laki - laki. Sedangkan yang terdiagnosis oleh tenaga kesehatan hanya mencapai 9,4 persen. Ini artinya masih banyak penderita penyakit hipertensi yang belum terjangkau dan terdiagnosa oleh tenaga kesehatan dan belum menjalani pengobatan sesuai anjuran tenaga kesehatan. Hal tersebut menyababkan penyakit hipertensi adalah sebagai salah satu penyebab kematian tertinggi di Indonesia.

Hipertensi dibagi menjadi dua golongan yaitu hipertensi esensial (primer) merupakan hipertensi yang tidak diketahui penyebabnya dan ada kemungkinan karna faktor keturunan atau genetik (90\%). Hipertensi sekunder yaitu hipertensi yang merupakan akibat dari adanya penyakit lain. Faktor makanan yang sangat berpengaruh adalah kelebihan lemak (obesitas), jarang berolahraga, kurang makan buah dan sayuran, mengonsumsi garam dapur yang terlalu tinggi,meminum terlalu banyak kopi atau minuman lain yang mengandung kafein, merokok dan terlalu banyak mengonsumsi minuman keras. Penderita hipertensi tercatat banyak dari usia 50-60 tahun dikarnakan pada usia lanjut fungsi organ tubuh mulai menurun (Adib M, 2009). Keputusan untuk memberikan pengobatan farmakologi mempertimbangkan beberapa faktor, yaitu derajad kenaikan TD, adanya kerusakan organ target, dan adanya penyakit kardiovaskuler (Levi D, 1996)(Klungel OH,2001). Tujuan pengobatan adalah menurunkan morbiditas dan mortabilitas akibat hipertensi dengan memelihara tekanan darah sistolik di bawah $140 \mathrm{mmHg}$, tekanan diastolic dibawah $90 \mathrm{mmHg}$ disamping mencegah resiko penyakit kardiovaskuler lainnya. Beberapa hal yang perlu dipertimbangkan dalam penggunaan obat anti hipertensi, yaitu mulai saat mulai pengobatan gunakanlah dosis yang kecil, dan pergunakan obat dengan menggunakan dosis tunggal yang dapat mencakup efek selama 24 jam (WHO, 1999).

Melihat kondisi tersebut dimana pemilihan terapi obat bukanlah hal yang mudah, perlu dilakukan penelitian mengenai profil tentang pemberian obat pada pasien hipertensi. 


\section{METODOLOGI PENELITIAN}

\section{A. Jenis dan Rancangan Penelitian}

Penelitian ini menggunakan desain penelitian deskriptif yaitu penelitian yang dimaksudkan untuk mengangkat fakta, keadaan dan variabel yang terjadi selama penelitian berlangsung dan menyajikan apa adanya. Fakta dan keadaan yang ingin digambarkan oleh peneliti dalam penelitian ini adalah profil penggunaan obat pada penyakit pasien Hipertensi di puskesmas marawola

\section{B. Waktu dan Tempat Penelitian.}

Waktu penelitian dilaksanakan pada bulan Januari-Maret 2015 di Puskesmas Marawola

\section{Prosedur Kerja}

Prosedur kerja, penelitian studi peresepan obat Hipertensi di puskesmas Marawola:

1. Persiapan penelitian.

2. Pengambilan surat pengantar dari direktur Akademi Farmasi Medika Nusantara Palu.

3. Penyerahan surat ke puskesmas Marawola bagian Tata usaha, ditunjukan kepada kepala puskesmas.

4. Setelah mendapat izin dari kepala puskesmas Marawola kemudian memberikan surat pernyataan ke bagian Instalasi Farmasi Puskesmas Marawola.

5. Penelitian melakukan pengumpulan data dari bagian Instalasi Farmasi Puskesmas Marawola.

6. Data yang telah dikumpulkan kemudian diperiksa kembali apakah data yang diperlukan sudah lengkap dan sesuai dengan penelitian. Apabila belum lengkap, peneliti meminta kembali kepada petugas puskesmas berdasarkan keperluan peneliti.

7. Melakukan pengolahan data dan analisis.

8. Memberikan pembahasan dari hasil pengolahan data dan kesimpulan.

\section{D.Pengelolaan Data (Tekhnik Analisis).}

Dalam penelitian ini secara deskriptif dalam bentuk Tabel dan Diagram batang dan narasi. Penggunaan metode deskriptif pada pola peresepan obat pada penyakit Hipertensi di puskesmas Marawola.

- Perhitungan presentase dari data penelitian :

Rumus presentase peresepan obat Hipertensi :

$\%=\frac{\text { jumlah obat } \text { Hipertensi dalam perbulan }}{\text { jumlah } \text { obat dalam pertahun }} \times 100 \%$

Keterangan: $\mathrm{n}=$ Jumlah nilai yang diperoleh .

$\mathrm{N}=$ Jumlah keseluruhan

$\%$ = Jumlah presentase. 


\section{HASIL DAN PEMBAHASAN}

Hipertensi atau tekanan darah tinggi dikenal luas sebagai penyakit kardiovaskuler yang merupakan suatu penyakit dengan kondisi medis yang beragam seperti pada kebanyakan kasus hipertensi dapat berakibat terjadinya gangguan jantung gagal ginjal maupun penyakit serebrovaskuler.

Secara umum penyebab penyakit hipertensi adalah meningkatnya aktifitas sistem saraf simpatik mungkin berhubungan dengan meningkatnya respon terhadap stress psikososial, asupan natrium yang berlebihan, tidak cukupnya asupan kalium dan kalsium dalam tubuh, produksi berlebihan hormon yang menahan natrium dan kurangnya aktifitas seperti berolahraga serta tidak teraturnya pola makan

Penelitian ini menggunakan desain penelitian deskriptif yaitu penelitian yang dimaksudkan untuk mengangkat fakta, keaadaan dan variabel yang terjadi selama penelitian berlangsung dan menyajikan apa adanya.

Penelitian Profil Penggunaan Obat Pada Pasien Hipertensi dipuskesmas Marawola periode Januari - Maret 2015 dengan hasil sebagai berikut.

\section{Karakteristik Pasien}

Tabel 1. Presentase Klasifikasi Penderita Hipertensi Berdasarkan jenis kelamin.

\begin{tabular}{|l|l|l|l|}
\hline NO & Jenis Kelamin & $\begin{array}{c}\text { Jumlah } \\
\text { (orang) }\end{array}$ & $\begin{array}{c}\text { Presentase } \\
(\%)\end{array}$ \\
\hline 1 & Laki - laki & 43 & 45,74 \\
\hline 2 & Perempuan & 51 & 54,26 \\
\hline \multicolumn{2}{|c|}{ Total } & 94 & 100 \\
\hline
\end{tabular}

Hasil analisa data $1 . \quad$ : Menunjukan bahwa presentase dari penderita penyakit Hipertensi berdasarkan jenis kelamin yaitu Laki - laki sebanyak 43 orang $(45,74 \%)$ dan perempuan sebanyak 51 orang $(54,26 \%)$. Pada hasil analisa ini didapatkan pasien Hipertensi lebih banyak terjadi pada perempuan, dibandingkan dengan laki laki. Untuk lebih jelasnya dapat dilihat pada grafik dibawah ini.

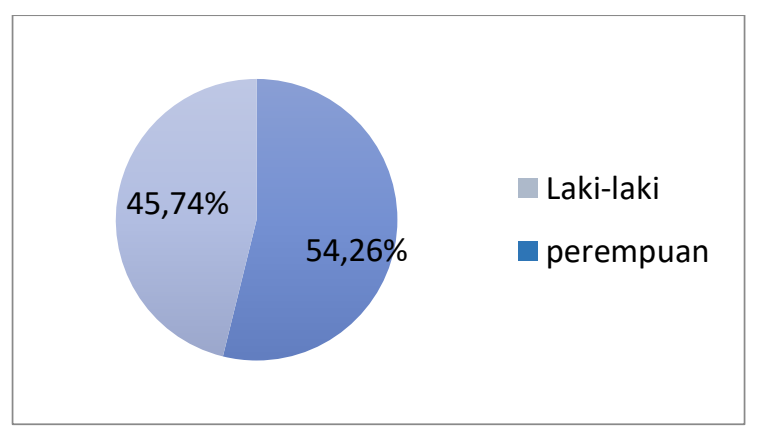

Diagram 1 : Distribusi Jumlah penderita Hipertensi berdasarkan jenis kelamin.

\section{Distribusi pasien berdasarkan usia.}

Tabel 2. presentase klasifikasi penderita Hipertensi berdasarkan usia. 


\begin{tabular}{|l|l|l|l|}
\hline No. & $\begin{array}{l}\text { Usia Penderita } \\
\text { (tahun) }\end{array}$ & $\begin{array}{r}\text { Jumlah } \\
\text { (orang) }\end{array}$ & Presentase(\%) \\
\hline 1. & $<40$ & 7 & 7,45 \\
2. & $40-49$ & 24 & 25,53 \\
3. & $50-59$ & 29 & 30,85 \\
4. & $60-69$ & 18 & 19,15 \\
5. & $70-79$ & 13 & 13,83 \\
6. & 80 & 3 & 3,19 \\
\hline & Total & 94 & 100 \\
\hline
\end{tabular}

Hasil analisa data tabel 4.2 :

Menunjukan penderita Hipertensi berdasarkan usia $<40$ tahun sebanyak 7 orang dengan presentase $7,45 \%$, usia 40 49 tahun sebanyak 24 orang dengan presentase 25,53\%, usia 50 - 59 tahun sebanyak 29 orang dengan presentase $30,85 \%$, usia 60 - 69 tahun sebanyak 18 dengan presentase 19,15\%, usia 70 - 79 tahun sebanyak 13 orang dengan presentase $13,83 \%$ dan usia >80 tahun sebanyak 3 orang dengan presentase 3,19\%. Dari data diperoleh penderita Hipertensi lebih banyak terjadi pada usia 50 - 59 tahun sebanyak 29 orang dengan presentase 30,85\%. Untuk lebih jelasnya dapat dilihat pada grafik dibawah ini

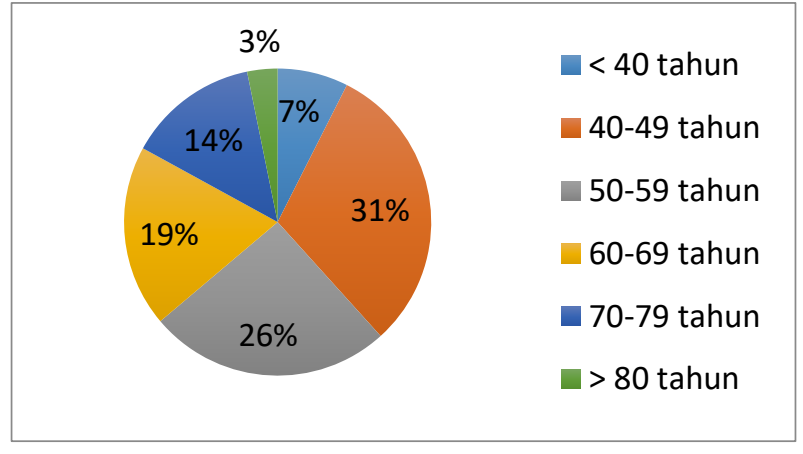

Diagram 2 : Distribusi jumlah penderita Hipertensi berdasarkan usia.

\section{Pengobatan Hipertensi di Puskesmas Marawola}

Tabel 3. Presentase penggunaan obat Hipertensi pada penderita Hipertensi.

\begin{tabular}{|c|c|l|c|c|}
\hline No & Kelas terapi & Nama Obat & Jum & $\begin{array}{c}\text { Presen } \\
\text { tase } \\
(\%)\end{array}$ \\
\hline 1 & $\begin{array}{l}\text { Antipiretik dan } \\
\text { Analgesik }\end{array}$ & $\begin{array}{l}\text { PCT } \\
\text { Asam } \\
\text { mefenamat }\end{array}$ & 91 & $\begin{array}{c}13,32 \\
2,35\end{array}$ \\
\hline 2. & Antiangina & $\begin{array}{l}\text { Isosorbid } \\
\text { dinitrat }\end{array}$ & 66 & 17,23 \\
\hline 3 & Ace Inhibitor & Nifedipin & 7 & 1,83 \\
\hline 4. & Dopamin & 1 & 0,26 \\
\hline 5 & Beta blocker & Diltiazem & 2 & 0,52 \\
\hline & Calcium chanel & Bisprolol & 6 & 1,57 \\
\hline & Amlocker & Nikardipine & 21 & 19,06 \\
\hline & Amdixal & 1 & 0,26 \\
\hline
\end{tabular}




\begin{tabular}{|l|l|l|r|l|}
\hline & & Novarsk & 1 & 0,26 \\
\hline 6 & Alpha Blocker & Hytrin & 4 & 1,05 \\
& & Bunasozin & 1 & 0,26 \\
\hline \multirow{4}{*}{7} & Syok, & Dobutami & 3 & 0,78 \\
& $\begin{array}{l}\text { Glikosida } \\
\text { jantung, } \\
\text { Vasodilator }\end{array}$ & ne & 11 & 2,87 \\
& Digoksin & 1 & 0,26 \\
& Pentoksifil & & \\
\hline \multicolumn{2}{|c|}{ Total } & & \\
\hline \multicolumn{2}{|c|}{} & 383 & 100 \\
\hline
\end{tabular}

Hasil analisa data table 3 : Menunjukan penggunaan obat pada penyakit Hipertensi yaitu Paracetamol sebanyak 13,32\%, Asam mefinamat 2,35\%, Ibuprofen 0,26\%, Isosorbid dinitrat 17,23\%, Nifedipin 1,83\%, Dopamin 0,26\%, Diltiazen 0,52\%, Captopril 19,06\%,

Propanolol 18,54\%, Bisoprolol 1,57\%, Amlodipine 13,84\%, Nimodipine 5,48\%, Amdixal 0,26\%, Ceremax 0,26\%, HCT 1,05\%, Bunazosin 0,26\%, Dobutamine 0,78\%, Digoksin 2,87\%, Pentoksifilin 0,26\%. Dari data diperoleh obat yang paling banyak digunakan adalah Captopril 19,06\%. Untuk lebih jelasnya dapat dilihat pada grafik dibawah ini.

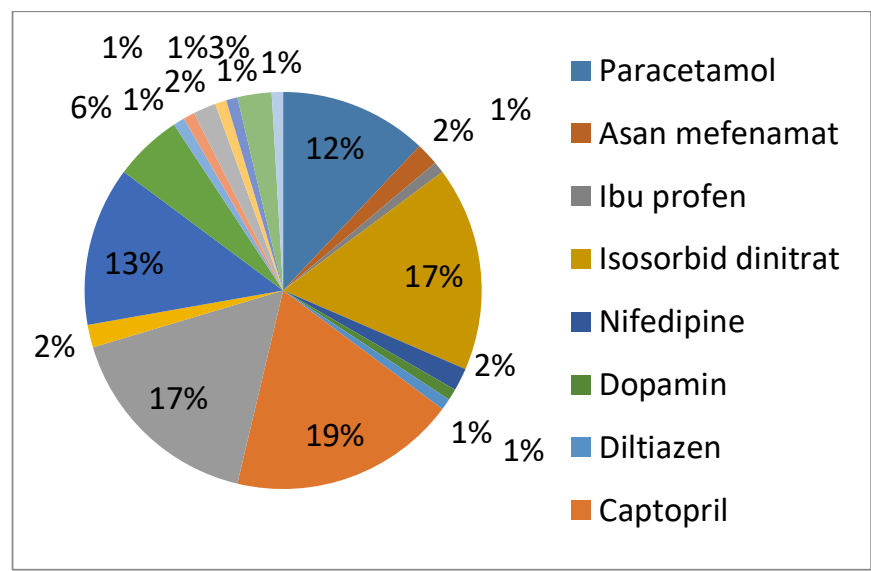

Diagram 3 : Distribusi penggunaan obat Hipertensi pada penderita Hipertensi.

Dari data yang diperoleh obat yang paling banyak digunakan adalah Captopril 19,06\%, Captopril merupakan obat antihipertensi yang temasuk dalam golongan Ace inhibitor, sering kali digunakan dalam mengatasi penyakit hipertensi maupun terapi gagal jantung ringan hingga sedang. Alasan pemilihan pengobatan menggunakan obat - obat tersebut bukan karena adanya tanda dan gejala karena pasien dengan hipertensi esensial biasanya tidak ada gejala, penemuan fisik yang utama adalah meningkatnya tekanan darah. Pengukuran rata - rata dua kali atau lebih dalam waktu kontrol ditentukan untuk mendiagnosis bahwa adanya penyakit hipertensi. Tekanan darah ini digunakan untuk mendiagnosis dan mengklasifikasi tekanan sesuai dengan tingkatanya. 
Tabel 4. Penggunaan obat pendamping pada penderita Hipertensi.

\begin{tabular}{|l|l|l|}
\hline No & Kelas Terapi & Nama Generik \\
\hline 1 & $\begin{array}{l}\text { Vitamin dan } \\
\text { Mineral }\end{array}$ & $\begin{array}{l}\text { Fundifar } \\
\text { Vitamin E }\end{array}$ \\
\hline
\end{tabular}

4. Identifikasi Berdasarkan DepKes. RI. Pharmaceutical Care untuk penyakit Hipertensi tahun 2005.

Tabel 5.Presentase ketepatan dan ketidak tepatan penggunaan obat Hipertensi berdasarkan DepKes. RI. Pharmaceutical Care untuk penyakit Hipertensi tahun 2005

\begin{tabular}{|c|c|c|c|c|c|}
\hline \multirow[t]{2}{*}{ Periode } & \multirow{2}{*}{$\begin{array}{c}\text { Jumlah } \\
\text { obat }\end{array}$} & \multicolumn{4}{|c|}{$\begin{array}{lr}\text { Pedoman } & \text { Pengobatan } \\
\text { Berdasarkan DepKes. RI. } & \text { Rare } \\
\text { Pharmaceutical } & \text { Care } \\
\text { Penyakit } & \text { Hipertensi } \\
\text { Tahun 2005 } & \end{array}$} \\
\hline & & Tepat & $\%$ & $\begin{array}{l}\text { Tidak } \\
\text { Tepat }\end{array}$ & $\%$ \\
\hline $\begin{array}{c}\text { Januari } \\
\text { - Maret } \\
2015\end{array}$ & 94 & 94 & 100 & 0 & 0 \\
\hline
\end{tabular}

Hasil analisa data tabel 4.5 : Menunjukan tepat dan ketidak tepatan penggunaan obat Hipertensi berdasarkan DepKes. RI. Pharmaceutical care untuk penyakit Hipertensi tahun 2005 diperoleh tepat $100 \%$ dan tidak tepat $0 \%$.
Berdasarkan hasil presentase tersebut penggunaan obat pada penderita penyakit hipertensi dipuskermas Marawola sudah tepat dan benar dengan standar pengobatan DepKes. RI. Pharmaceutical care untuk penyakit hipertensi 2005. Tepat dimaksud adalah indikasi. Tepat indikasi adalah ketepatan pemilihan obat, yang dipandang perlu diberikan kepada pasien oleh tenaga medis pada saat mendiagnosis, sehingga pasien tertangani secara medis

\section{KESIMPULAN}

Berdasarkan hasil penelitian dan pembahasan, maka dapat disimpulkan sebagai berikut:

Pola penggunaan obat pada pasien Hipertensi dipuskesmas Marawola adalah pemberian obat Hipertensi semuanya sudah tepat indikasi $100 \%$. Hal ini menunjukan bahwa obat yang diberikan dan digunakan oleh pasien Hipertensi sudah sesuai dengan pedoman berdasarkan pengobatan Depkes. RI pharmaceutical care untuk penyakit hipertensi tahun 2005.

\section{DAFTAR PUSTAKA}

DRS. Tan Hoan Tjay,. Obat-obat penting, edisi enam 2008 penerbit PT Elex media komputindo. Jakarta 
Sutrisni, L,.S.Alam, dan I Hadibroto. Diabetes. Jakarta :PT Gramedia Pustaka Utama ; 2006

Saraswati, S. Diet sehat untuk penyakit asam urat, Diabetes, Hipertensi, dan stroke. Jogjakarta : Aplus ; 2009

Adib, M, 2009, cara mudah memahami dan menghindari Hipertensi, Jantung, dan Stroke. Edisi ke-2, Yogyakarta: Dianloka Printika

Preventiob of hypertension. U.S. Departemen of health and human services. 1993. Available fromURLhttp:/www.nhlbi.nih.gov/health/ prof/heart/pphbp.htm

Levi D , Larson MG, Varsan RS, Kannel WB. KK The Progression From hypertension to congestive heart failure. JAMA 1996;275;1557;1562

Klungel $\mathrm{OH}$, Hekcbert,SR, Longstreth Jr WT Furberg CD, Kaplan RC, Smith NL et al.
Antihypertensive drug therapes and the riks of ischemic Med 2001;161;3743

WHO. Guidelines for management of hypertension Geneva: WHO;1999. Available fromURLhttp:/www.who.int/ncd/cvd/ht guide.html

Keputusan Menteri Kesehatan RI Nomor 128/MENKES/SK/II2004 tentang kebijakan dasar pusat kesehatan masyarakat. Menkes RI. Jakarta

DepKes RI. Direktorat Jenderal Bina Kefarmasian dan Alat Kesehatan \& Direktorat Bina Farmasi Komunitas dan Klinik, pharmaceutical care ntuk penyakit Hipertensi. 2005. 